NBER WORKING PAPER SERIES

ON THE OPTIMAL INFLATION RATE

Markus K. Brunnermeier

Yuliy Sannikov

Working Paper 22133

http://www.nber.org/papers/w22133

\author{
NATIONAL BUREAU OF ECONOMIC RESEARCH \\ 1050 Massachusetts Avenue \\ Cambridge, MA 02138 \\ March 2016
}

We thank Itamar Drechsler for helpful comments and Yann Koby, Christian Wolf and especially Sebastian Merkel for excellent research assistance. The views expressed herein are those of the authors and do not necessarily reflect the views of the National Bureau of Economic Research.

At least one co-author has disclosed a financial relationship of potential relevance for this research. Further information is available online at http://www.nber.org/papers/w22133.ack

NBER working papers are circulated for discussion and comment purposes. They have not been peer-reviewed or been subject to the review by the NBER Board of Directors that accompanies official NBER publications.

(C) 2016 by Markus K. Brunnermeier and Yuliy Sannikov. All rights reserved. Short sections of text, not to exceed two paragraphs, may be quoted without explicit permission provided that full credit, including $\odot$ notice, is given to the source. 
On the Optimal Inflation Rate

Markus K. Brunnermeier and Yuliy Sannikov

NBER Working Paper No. 22133

March 2016

JEL No. E44,E51,E52

\begin{abstract}
In our incomplete markets economy financial frictions affect the optimal inflation target. Households choose portfolios consisting of risky (uninsurable) capital and money. Money is a bubbly store of value. The market outcome is constrained Pareto inefficient due to a pecuniary externality. Each individual agent takes the real interest rate as given, while in the aggregate it is driven by the economic growth rate, which in turn depends on individual portfolio decisions. Higher inflation due to higher money growth lowers the real interest rate (on money) and tilts the portfolio choice towards physical capital investment. The optimal inflation target boosts growth and welfare and is higher for emerging market economies.
\end{abstract}

\author{
Markus K. Brunnermeier \\ Princeton University \\ Department of Economics \\ Bendheim Center for Finance \\ Princeton, NJ 08540 \\ and NBER \\ markus@princeton.edu \\ Yuliy Sannikov \\ Department of Economics \\ 208 Fisher Hall \\ Princeton University \\ Princeton, NJ 08544 \\ sannikov@gmail.com
}




\title{
On the Optimal Inflation Rate
}

\author{
Markus K. Brunnermeier and Yuliy Sannikov*
}

March 29, 2016

\begin{abstract}
In our incomplete markets economy financial frictions affect the optimal inflation target. Households choose portfolios consisting of risky (uninsurable) capital and money. Money is a bubbly store of value. The market outcome is constrained Pareto inefficient due to a pecuniary externality. Each individual agent takes the real interest rate as given, while in the aggregate it is driven by the economic growth rate, which in turn depends on individual portfolio decisions. Higher inflation due to higher money growth lowers the real interest rate (on money) and tilts the portfolio choice towards physical capital investment. The optimal inflation target boosts growth and welfare and is higher for emerging market economies.
\end{abstract}

\section{Introduction}

How do financial frictions affect the optimal inflation rate? Can financial frictions alone annul the long-run super-neutrality of money? Should the inflation rate be higher in emerging market economies with less developed financial markets than in advanced economies, as is currently observed? 7 ]

To answer these questions we set up an incomplete markets model in which households choose portfolios consisting of risky (physical) capital and money. Physical capital holdings are encumbered with idiosyncratic risk. Financial frictions prevent the diversification of the idiosyncratic risk. Our analysis in this paper can be seen as a simplified discrete-time version of the "I Theory of Money" (Brunnermeier and Sannikov, 2015) - but without the "I", the intermediaries and inside money, and with an exclusive focus on the long-run steady state.

Like in Samuelson's (1958) OLG and in Bewley's (1980) uninsurable endowment risk model, money serves as a store of value and can have positive value despite the fact that it never pays any dividends. Diamond (1965) introduces physical capital in Samuelson's OLG model and Aiyagari (1994) in Bewley's incomplete markets setting (but capital drives out money). In our setting, money and physical capital coexist and agents choose portfolios. Like in Diamond and Aiyagari, the market outcome is dynamically inefficient. In contrast, however, to Diamond and Aiyagari, in which the interest rate is too low and savings and physical capital investment are excessive, in our setting the real risk-free interest rate is too high and the investment rate is inefficiently low.

\footnotetext{
*Brunnermeier: Princeton University, Department of Economics, Princeton, NJ, 08544, email: markus@princeton.edu. Sannikov: Princeton University, Department of Economics, Princeton, NJ, 08544, USA, email: Sannikov@princeton.edu. We thank Itamar Drechsler for helpful comments and Yann Koby, Christian Wolf and especially Sebastian Merkel for excellent research assistance.

${ }^{1}$ The differences in inflation targets between emerging market and advanced economies are documented e.g. in Table 1 in Fraga, Goldfajn, and Minella (2004) and Table 4.1 of International Monetary Fund (2005).
} 
The market outcome is constrained Pareto inefficient due to pecuniary externalities. Each individual agent takes the real interest rate as given, while in the aggregate it is driven by the economic growth rate, which in turn depends on individual portfolio decisions. Higher inflation due to higher money growth lowers the real interest rate (on money) and tilts the portfolio choice towards physical capital investment. This boosts the overall physical investment and endogenous growth rate.

We are able to solve the model and conduct the welfare analysis in closed form. We show that there is an optimal level of long-run inflation in a setting in which seigniorage is handed out in a wealthdistribution-neutral way. A government that faces the same constraints as markets can orchestrate a Pareto welfare improvement simply by printing the right amount of money. Second, we show that in countries with higher idiosyncratic risk, e.g. because the domestic financial sector is less developed, the optimal inflation rate is higher.

Most existing literature explores various rationales other than financial frictions to determine the optimal inflation and money growth rate ${ }^{2}$ The Friedman Rule advocates a policy that minimizes the cost of holding currency. Hence, currency should appreciate at the real risk-free rate of return, which implies deflation (unless currency, like short-term government debt, earns interest). Most New Keynesian models with price stickiness à la Calvo (1983) recommend a zero inflation rate in steady state. Zero inflation minimizes the price dispersion between firms that accidentally had a chance to readjust their prices and those who did not have this opportunity. A higher inflation target can be justified if nominal interest rates are subject to the zero lower bound (ZLB). Hitting the ZLB may lead to an excessively high real interest rate causing output losses. In our setting the real interest rate is also too high, even without the ZLB, and capital investment is depressed. Tobin (1972) argues in favor of a positive inflation rate in order to overcome frictions resulting from downward wage rigidities. Phelps (1973) criticizes the Friedman rule and conjectures that the inflation tax should be part of an overall optimal tax scheme. Yet, the Friedman rule has turned out to be remarkably robust. A higher inflation tax may be optimal, only if it counteracts some monopolistic distortions or extends to an otherwise untaxable large shadow economy. In our setting inflation acts as a Pigouvian tax on money holding to overcome pecuniary externalities.

\section{The Economy}

\subsection{Model Setup}

Our economy is populated by a continuum of households with identical preferences but potentially different levels of wealth. Each household manages a private firm which operates a linear production technology with capital as the single input. Firms are subject to idiosyncratic, (real) cash-flow shocks of size proportional to the level of capital they manage. In addition, households can hold money, a bubble asset, which does not pay any dividends nor provides any other intrinsic service.

Time is divided into discrete intervals of length $\Delta t$, indexed by $j 3^{3}$ The timing within each period is as follows: Households enter period $j$ with physical capital holdings $k_{j}$ and nominal money holdings $m_{j}$. First, the physical capital produces output $A k_{j} \Delta t$, cash-flow shocks are realized and the household receives transfers from the government's seigniorage income. Second, households choose the investment rate $\iota_{j}$. That is, they decide how many output units $\iota_{j} k_{j} \Delta t$ they use to produce new

\footnotetext{
${ }^{2}$ See e.g. Schmitt-Grohé and Uribe $(2010)$ and Woodford $(1990)$.

${ }^{3} \mathrm{As}$ is common in discrete time models, we sum Hows and ignore compounding effects within a $\Delta t$-period, while across periods we take compounding into account. For $\Delta t=1$ our model resembles a standard discrete time model.
} 
physical capital. Consequently, physical capital grows to $k_{j+1}=\left(1+\left(\Phi\left(\iota_{j}\right)-\delta\right) \Delta t\right) k_{j}$, where $\delta$ is the depreciation rate, and the concave function $\Phi(\iota)$ reflects investment adjustment costs. Specifically, we assume the following functional form $\Phi(\iota)=\frac{1}{\kappa} \log (1+\kappa \iota)$ with adjustment cost parameter $\kappa$. At the end of a period, households make their portfolio and consumption choices. That is, they trade physical capital, money and output goods to obtain the new capital holding $k_{j+1}$ and nominal money holding $m_{j+1}$ and consume the rest.

The consumption good serves as our numeraire. We restrict attention to equilibria with constant real price of physical capital $q$. The real value of aggregate physical capital, $K_{j}$, is $q K_{j}$. The real value of total money supply is $p K_{j}$. In other words, $p \geq 0$ is the real value of money normalized by the size of the economy, measured by the aggregate capital stock, $K_{j}{ }^{4}$ The total wealth in the economy is $(p+q) K_{j}$. Given the quantity of money of $M_{j}$, the price level in the economy is $\mathcal{P}_{j}:=\frac{M_{j}}{p K_{j}}$. The government chooses the money growth rate $\mu$, i.e. $M_{j+1}=(1+\mu \Delta t) M_{j}$, which impacts the real return on money $R_{j}^{m}$. The seigniorage revenues are redistributed in proportion to each household's

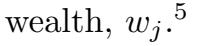

We assume that all household maximize expected log utility with a time preference rate of $\rho \Delta t$. Given initial capital and nominal money holdings $k_{0}$ and $m_{0}$, any household in the economy solves the problem

$$
\begin{gathered}
\max _{\left\{c_{j}, k_{j+1}, m_{j+1}, \iota_{j}\right\}_{j=0}^{\infty}} E\left[\sum_{j=0}^{\infty}\left(\frac{1}{1+\rho \Delta t}\right)^{j} \log c_{j} \cdot \Delta t\right] \\
\text { s.t. } \quad\left(c_{j}+\iota_{j} k_{j}\right) \Delta t+q k_{j+1}+\frac{m_{j+1}}{\mathcal{P}_{j}}= \\
A k_{j} \Delta t+z_{j}+q\left(1+\left(\Phi\left(\iota_{j}\right)-\delta\right) \Delta t\right) k_{j}+R_{j}^{m} \frac{m_{j}}{\mathcal{P}_{j-1}}+\tau_{j} w_{j} \\
w_{j}=q k_{j}+\frac{m_{j}}{\mathcal{P}_{j-1}}
\end{gathered}
$$

where $z_{j}$ are real cash flow shocks and $\tau_{j} w_{j}$ are transfers from the government ${ }^{6}$ Households face idiosyncratic cash-flow shocks $z_{j}$ which are proportional to the size of their business measured in the units of capital employed in production:

$$
z_{j}=\sigma \varepsilon_{j} \sqrt{\Delta t} k_{j}
$$

where $\varepsilon_{j}$ is an iid shock, both over time and across households, with zero mean and unit variance 7 $\sigma>0$ is a parameter. The shock is scaled by $\sqrt{\Delta t}$ instead of $\Delta t$ to ensure that its impact does not become smaller with decreasing period length $\Delta t$. In sum, all flow variables contain a $\Delta t$-term, all shocks a $\sqrt{\Delta t}$-term, while stocks do not depend on the length of the time period.

\footnotetext{
${ }^{4} p$ is also assumed to be a time-invariant constant, but this assumption is not essential and just made for convenience: one can show that a time-invariant $q$ implies a time-invariant $p$ in any equilibrium.

${ }^{5}$ In a world in which interest is paid on outside money (reserves) $\mu$ refers to the money growth beyond the interest payment while overall inflation is growing with the total money growth rate.

${ }^{6}$ Money holdings $m_{j}$ in the beginning of period $j$ are divided by $\mathcal{P}_{j-1}$, not $\mathcal{P}_{j}$, because $R_{j}^{m}$ is already the real rate of return.

${ }^{7}$ Note that the distribution needs to have bounded support to avoid the possibility of wealth becoming negative. Unbounded normally distributed shocks only work in the continuous-time limit.
} 


\subsection{Optimality Conditions}

Lemma 1. The optimal internal investment rate $\iota^{*}$ is an intra-period problem, solves $q=\frac{1}{\Phi^{\prime}\left(\iota^{*}\right)}=$ $1+\kappa \iota^{*}$ and is identical across all households and constant over time.

Note that if all households choose the same investment rate $\iota^{*}$, the law of motion of the aggregate capital stock is

$$
K_{j+1}=(1+\underbrace{\left(\Phi\left(\iota^{*}\right)-\delta\right)}_{g:=} \Delta t) K_{j} .
$$

The (gross) returns on physical capital and on money are then given by

$$
\begin{aligned}
R_{j}^{k} & =1+\left(\frac{A-\iota^{*}}{q}+g\right) \Delta t+\frac{\sigma}{q} \varepsilon_{j} \sqrt{\Delta t}, \\
R_{j}^{m} & =\frac{1+g \Delta t}{1+\mu \Delta t} .
\end{aligned}
$$

Let the "portfolio return" if the household holds a fraction $x^{k}$ in physical capital and fraction $\left(1-x^{k}\right)$ in money be

$$
R_{j}^{p}\left(x_{j}^{k}\right):=x_{j}^{k} R_{j}^{k}+\left(1-x_{j}^{k}\right) R_{j}^{m}+\tau_{j}
$$

We include seigniorage transfers $\tau_{j}$ as they are also proportional to household wealth. Denote by $w_{j}^{\prime}=q k_{j} R_{j}^{k}+\frac{m_{j}}{\mathcal{P}_{j-1}} R_{j}^{m}+\tau_{j} w_{j}$ household wealth immediately before consumption (sometimes referred to as "cash at hand"), i.e. for period $j, w_{j}^{\prime}-c_{j} \Delta t=w_{j+1}$. Given the optimal investment rate $\iota^{*}$ one can then rewrite the household's problem as a Bellman equation in terms of the single state variable $w 8$

$$
V\left(w^{\prime}\right)=\max _{c, x^{k}}\left(\log c \cdot \Delta t+\frac{1}{1+\rho \Delta t} E\left[V\left(R^{p}\left(x^{k}\right)\left(w^{\prime}-c \Delta t\right)\right)\right]\right)
$$

This is a standard consumption-savings and portfolio optimization problem. We conjecture a value function of the form $V\left(w^{\prime}\right)=\alpha_{0}+\alpha_{1} \log w^{\prime}$, where $\alpha_{0}, \alpha_{1}$ are undetermined coefficients. Using this conjecture the right-hand side of the problem becomes

$$
\frac{1}{1+\rho \Delta t} \alpha_{0}+\max _{c}\left(\log c \cdot \Delta t+\frac{1}{1+\rho \Delta t} \alpha_{1} \log \left(w^{\prime}-c \Delta t\right)\right)+\max _{x^{k}} \frac{1}{1+\rho \Delta t} \alpha_{1} E\left[\log R^{p}\left(x^{k}\right)\right]
$$

This conveniently separates the maximization problems with respect to $c$ and $x^{k}$. The consumption problem can be solved explicitly and doing so also verifies the conjectured functional form of the value function.

Lemma 2. The optimal consumption level is $c^{*}=\frac{\rho}{1+\rho \Delta t} w^{\prime}$.

We solve the portfolio choice problem for an approximate solution which becomes exact as $\Delta t \rightarrow 0$, i.e. in the continuous-time limit. This solution is obtained by evaluating $E\left[\log R^{p}\left(x^{k}\right)\right]$ using a Taylor

\footnotetext{
${ }^{8}$ Henceforth we suppress period subscripts in our notation, whenever making them explicit does not provide additional clarity.
} 
expansion around $R^{p}\left(x^{k}\right)=1$ up to a term of order $\Delta t$. Since $R^{p}\left(x^{k}\right)=1+O(\sqrt{\Delta t})$, we need to include only terms up to degree 2. Notice also that $\left(R^{p}\left(x^{k}\right)-1\right)^{2}=x^{k} \frac{\sigma^{2}}{q^{2}} \varepsilon^{2} \Delta t+o(\Delta t)$. Hence,

$$
\begin{aligned}
E\left[\log R^{p}\left(x^{k}\right)\right] & =E\left[\left(R^{p}\left(x^{k}\right)-1\right)-\frac{1}{2}\left(R^{p}\left(x^{k}\right)-1\right)^{2}\right]+o(\Delta t)= \\
& \approx\left(g-\tau+x^{k}\left(\frac{A-\iota^{*}}{q}+\mu\right)-\frac{1}{2}\left(x^{k}\right)^{2} \frac{\sigma^{2}}{q^{2}}\right) \Delta t
\end{aligned}
$$

where in the last equation we use the fact that $\varepsilon$ has zero mean and unit variance. This approximated portfolio problem is now quadratic in $x^{k}$ and straightforward to solve.

Lemma 3. The optimal portfolio share of capital is $x^{k *}=\frac{E\left[R^{k}-R^{m}\right]}{\operatorname{Var}\left[R^{k}-R^{m}\right]}=\frac{q\left(A-\iota^{*}\right)}{\sigma^{2}}+\frac{q^{2} \mu}{\sigma^{2}}$.

\subsection{Market Clearing Conditions}

The goods market clears if total output equals the sum of investment and consumption. Since individual cash-flow shocks cancel out in the aggregate and every households chooses the same $\iota^{*} 9$

$$
A K_{j} \Delta t=\iota^{*} K_{j} \Delta t+C_{j} \Delta t
$$

for every period $j$. By Lemma2 individual consumption is a constant fraction of end of period wealth before consumption $w_{j}^{\prime}$, which easily aggregates to $C_{j}=\frac{\rho}{1+\rho \Delta t} W_{j}^{\prime}$. By households' budget constraints,

$$
W_{j}^{\prime}=C_{j} \Delta t+W_{j+1}=\frac{\rho}{1+\rho \Delta t} \Delta t W_{j}^{\prime}+W_{j+1},
$$

hence

$$
W_{j}^{\prime}=(1+\rho \Delta t) W_{j+1}=(1+\rho \Delta t) \frac{K_{j+1}}{K_{j}}(p+q) K_{j}=(1+\rho \Delta t)\left(1+\left(\Phi\left(\iota^{*}\right)-\delta\right) \Delta t\right)(p+q) K_{j}
$$

Substituting this into the market clearing equation and dividing by $K_{j}$ yields

$$
A \Delta t=\iota^{*} \Delta t+\rho\left[\Delta t+\left(\Phi\left(\iota^{*}\right)-\delta\right)(\Delta t)^{2}\right](p+q) .
$$

The difference between end of period wealth $W^{\prime}{ }_{j}$ just before consumption and beginning of period wealth $W_{j}$ introduces the extra term $\left(\Phi\left(\iota^{*}\right)-\delta\right)$ in the goods market clearing condition, which reflects the growth of the economy within a period. This term does not arise when the period length $\Delta t$ vanishes or $\Phi\left(\iota^{*}\right)$ turns out to be equal to $\delta$. To be able to solve the model in closed form, we will in the following ignore this extra term of order $(\Delta t)^{2}{ }^{10}$ After dividing by $\Delta t$, the goods market clearing equation becomes

$$
A=\iota^{*}+\rho(p+q) .
$$

The capital market clears if aggregate capital demand equals capital supply, $\frac{x^{k *} W}{q}=K$. Using $W=(p+q) K$ and the optimal portfolio share from Lemma 3 yields

$$
\frac{1}{p+q}=\frac{A-\iota^{*}}{\sigma^{2}}+\frac{q \mu}{\sigma^{2}}
$$

The money market clears by Walras law.

\footnotetext{
${ }^{9}$ Capital letters are the aggregate counterparts of the lower-case letters in the individual decision problem.

${ }^{10} \mathrm{As}$ in the portfolio choice problem this means that we are approximating the model for small $\Delta t$ by its continuoustime limit. Note that we do not make two sequential approximations: the goods market clearing equation containing the $(\Delta t)^{2}$-term is exact and does not depend on the (approximated) solution to the portfolio choice problem.
} 


\subsection{Equilibrium}

Proposition 1. The following three equations approximatively characterize equilibrium prices $p, q$ and investment rate $\iota^{*}$ in discrete time and exactly in the continuous-time limit:

$$
\begin{aligned}
q & =1+\kappa \iota^{*} \\
\rho(p+q) & =A-\iota^{*} \\
\frac{\sigma^{2}}{q+p} & =A-\iota^{*}+q \mu
\end{aligned}
$$

While these three equations can in principle be solved in closed form, the solution is significantly simplified, if it is expressed in terms of a monotone transformation $\hat{\mu}:=x^{k *} \mu$ of money growth 11 To ensures that capital has a positive value irrespectively of the choice of $\mu>0$, we assume:

Assumption 1. $1+\kappa A>\kappa \sqrt{\rho} \sigma$

Proposition 2. In the "monetary equilibrium" in which money and capital have positive valu€12

$$
\begin{aligned}
p & =\frac{\sigma(1+\kappa \rho)}{\sqrt{\rho+\hat{\mu}}}-(1+\kappa A), \\
q & =1+\kappa A-\frac{\kappa \rho \sigma}{\sqrt{\rho+\hat{\mu}}}, \\
\iota^{*} & =A-\rho \frac{\sigma}{\sqrt{\rho+\hat{\mu}}},
\end{aligned}
$$

where the transformed money growth rate $\hat{\mu}=x^{k *} \mu$ is strictly increasing in $\mu$, and this equilibrium exists if $\hat{\mu}<\sigma^{2}\left(\frac{1+\kappa \rho}{1+\kappa A}\right)^{2}-\rho$.

There always exists a second moneyless equilibrium with $p=0, q=\frac{1+\kappa A}{1+\kappa \rho}, \iota^{*}=\frac{A-\rho}{1+\kappa \rho}$.

Proposition 2 reveals that in economies with high idiosyncratic risk, e.g. with poorly developed (internal) financial markets, money is more valuable. Indeed, for money to have positive value some minimum amount of idiosyncratic risk is necessary. Note that capital investment yields positive output $A k_{j}$, while money does not. For sufficiently low $\sigma$ or sufficiently high $A$, capital investment is too attractive and we are in a moneyless economy, i.e. $p=0$. Another interesting fact is that the capital depreciation rate $\delta$ does not affect prices nor the investment rate. However, it does affect the evolution of individual and aggregate capital and through it also households' overall utility level.

Note that in the moneyless equilibrium $x^{k *}=1$ and hence equilibrium is determined by the first two equations in Proposition 1 with $p=0$.

Most of the remaining discussion will be based on the monetary equilibrium of Proposition 2 in which the value of physical capital and money is positive.

\section{Welfare}

In this section we derive households' overall expected utility as a function of exogenous parameters and transformed money growth rate $\hat{\mu}$. The tractability of our framework allows us to characterize

\footnotetext{
${ }^{11}$ Due to the monotonic relationship, any qualitative statement in terms of $\hat{\mu}$ holds also in terms of $\mu$ and vice versa.

${ }^{12}$ These equations also hold for the special case of no capital adjustment costs, $\kappa=0$. In this case our model is a version of Angeletos (2007) but with money.
} 
welfare as a function of the portfolio return and asset prices in closed form without approximation. Going beyond that, and in order to characterize welfare as a function of exogenous parameters and of the government policy variable $\hat{\mu}$, we use our approximated equilibrium prices and returns. As our equilibrium results are exact in the continuous time limit, so are our welfare results.

Using the conjectured form of the value function, plugging in the optimal consumption solution from Lemma 2 and as a place holder $x^{k *}$ for the optimal portfolio choice, we solve for the unknown coefficients of the value function, $\alpha_{0}$ and $\alpha_{1}$ in terms of model parameters and the expected log portfolio returns $E\left[\log R^{p}\left(x^{k *}\right)\right]$ :

$$
\begin{gathered}
\alpha_{0}=V_{0}+\frac{1+\rho \Delta t}{\rho^{2}} \frac{E\left[\log R^{p}\left(x^{k *}\right)\right]}{\Delta t}, \\
\alpha_{1}=\frac{1+\rho \Delta t}{\rho},
\end{gathered}
$$

where $V_{0}$ only contains terms depending on $\rho$ and $\Delta t$. Thus, the value function is given by

$$
V\left(w^{\prime}\right)=V_{0}+\frac{1+\rho \Delta t}{\rho^{2}} \frac{E\left[\log R^{p}\left(x^{k *}\right)\right]}{\Delta t}+\frac{1+\rho \Delta t}{\rho} \log w^{\prime}
$$

Next, we would like to express welfare not as function of $w^{\prime}$, but as a function of the initial capital endowment $k_{0}$. Note that

$$
w_{0}^{\prime}=R_{0}^{p} w_{0}=R_{0}^{p}(p+q) k_{0} .
$$

Since the portfolio return $R_{0}^{p}$ depends on cash flow shocks in period $0, V\left(w_{0}^{\prime}\right)$ is from an ex-ante perspective random. Hence, we take expectations and obtain

$$
\begin{aligned}
U:=E\left[V\left(w_{0}^{\prime}\right)\right] & =V_{0}+\frac{1+\rho \Delta t}{\rho^{2}} \frac{E\left[\log R^{p}\left(x^{k *}\right)\right]}{\Delta t}+\frac{1+\rho \Delta t}{\rho}\left(E\left[\log R^{p}\left(x^{k *}\right)\right]+\log (p+q) k_{0}\right) \\
& =V_{0}+\frac{(1+\rho \Delta t)^{2}}{\rho^{2}} \frac{E\left[\log R^{p}\left(x^{k *}\right)\right]}{\Delta t}+\frac{1+\rho \Delta t}{\rho} \log (p+q) k_{0}
\end{aligned}
$$

Finally, we replace terms $E\left[\log R^{p}\right]$ and $p+q$ for which we have approximate closed-form expressions ${ }^{13}$ Recall $E\left[\log R^{p}\right]$ from the proof of Lemma 3 and $\iota^{*}, p+q$ from Proposition 2 Normalizing w.l.o.g. $k_{0}=1$, we obtain

Proposition 3. The expected utility of a household with initial capital stock $k_{0}=1$ is

$$
U=V_{0}+\frac{\frac{1}{\kappa} \log \left(1+\kappa A-\frac{\kappa \rho \sigma}{\sqrt{\rho+\hat{\mu}}}\right)-\delta+\rho-\frac{1}{2}(\rho+\hat{\mu})}{\rho^{2}}+\frac{\log \left(\frac{\sigma}{\sqrt{\rho+\hat{\mu}}}\right)}{\rho} .
$$

If we assume that all households are equally wealthy in the beginning we can simply integrate over all individual households' utility levels. That is, we can simply take an individual household's utility level as our economy wide welfare measure. In this case any welfare improvement is also a Pareto improvement ${ }^{14}$

\footnotetext{
${ }^{13}$ This is the only point at which we approximate our welfare derivation. The previous equation holds exactly for any $\Delta t>0$, but has the disadvantage that it includes $E\left[\log R^{p}\left(x^{k *}\right)\right]$ for which we do not have an exact closed form if $\Delta t>0$.

${ }^{14}$ Note that we are only assuming that households start with identical initial capital and money endowments. However, the wealth distribution in our economy will not stay the same over time. Some households will experience negative shocks and others positive shocks, such that the wealth distribution becomes more and more dispersed.
} 


\section{Optimal Money Growth and Inflation Rate}

Increasing the money growth rate increases inflation and lowers the real return on money. This encourages households to tilt their portfolio towards real assets at the expense of money holdings. The higher investment rate increases the real growth rate in the economy - a point originally made by Tobin (1965). Sidrauski (1967) showed that this is not welfare improving within a representative agent model, i.e. absent financial frictions. Our analysis revives Tobin's intuition by showing that the welfare-maximizing money growth rate is not zero in a setting with incomplete markets. In particular, if the (uninsurable) idiosyncratic risk is sufficiently large, the optimal money growth rate is positive.

Proposition 4 (Optimal money growth). There always exists a unique optimal growth rate of money $\mu^{*}$, which is positive (negative), if

$$
\sigma>(<) \frac{2 \sqrt{\rho}(A \kappa+1)}{1+2 \kappa \rho} .
$$

The competitive equilibrium outcome with $\mu=0$ is constrained Pareto inefficient except for the knife-edge case in which this condition holds with equality ${ }^{15}$

In addition, in the equilibrium with money growth rate $\mu^{*}$ money always has a strictly positive value.

The steady state (long-run) money growth rate affects the equilibrium allocation and economic growth. In short, money is not superneutral, despite the absence of any nominal rigidities and of the transaction role of money.

Corollary 1 (No Superneutrality). Money is not superneutral in our flexible price (steady state) economy since a steady state increase in money supply growth affects the steady state economic growth rate $\Phi\left(\iota^{*}\right)-\delta$.

As one increases money growth, output also increases. However, output maximizing money growth is excessive since it ignores the utility costs from bearing idiosyncratic risk. Indeed, it would make money so unattractive that it loses its value altogether, leading to a suboptimal welfare outcome as the last part of Proposition 4 reveals.

Zero money growth is also constrained Pareto inefficient, despite perfect competition and flexible prices. A government that faces the same constraints as markets can orchestrate a Pareto welfare improvement simply by printing the right amount of money. Competitive equilibrium prices are distorted due to pecuniary externalities. Each individual household does not internalize that, by tilting its portfolio towards real assets, it boosts real growth in the economy and with it also the real interest rate on money holdings. The social planner internalizes this pecuniary externality and an inflation tax works like a Pigouvian tax in this environment.

Finally, the optimal money growth rate is higher for economies with higher idiosyncratic risks.

\footnotetext{
${ }^{15}$ The optimal transformed money growth rate $\hat{\mu}^{*}$ is characterized by

$$
(1+\kappa A) \sqrt{\rho+\hat{\mu}^{*}}\left(2+\frac{\hat{\mu}^{*}}{\rho}\right)=\sigma\left(1+\kappa\left(2 \rho+\hat{\mu}^{*}\right)\right) .
$$
}


Proposition 5 (Comparative Statics). The optimal money growth rate $\mu^{*}$ is strictly increasing in idiosyncratic risk $\sigma{ }^{16}$

Proposition 5 provides an explanation for why emerging market economies have higher inflation targets than advanced economies in which financial markets enable better risk sharing. Inflation

$$
\pi=\mu-\left(\Phi\left(\iota^{*}(\mu)\right)-\delta\right)
$$

increases in $\mu$, but less than one-to-one since a higher $\mu$ also boosts the growth rate of the economy through a higher investment rate $\iota^{*}(\mu)$. Note that $\delta$ affects the optimal inflation target but not the optimal money growth rate.

\section{Robustness}

The result about the optimal money growth rate (Proposition 4) depends on the nature of shocks considered. For example, if contrary to our setup cash-flow shocks $z$ were nominal instead of real, one could eliminate uncertainty completely by inflating away the value of money. Thus, the welfaremaximizing money growth rate $\mu$ in such a setting would sufficiently high, such that value of money $p=0$. In contrast, in a setting with real cash flow shocks it is always optimal to have a strictly positive value of money, even if this can only be achieved with negative money growth.

In a different setting, if shocks were shocks to physical capital like in Brunnermeier and Sannikov (2014), the optimal money growth rate would be lower. With capital shocks an additional pecuniary externality emerges. A lower price of capital $q$ reduces the impact of idiosyncratic shocks. For example, when a machine breaks down it is cheaper to replace it. Since each individual decision maker takes $q$ as given, she does not internalize that by tilting the portfolio choice towards money, they together as a group lower $q$ and hence, lower the idiosyncratic risk exposure. This effect can offset the pecuniary externality discussed in the preceding section, such that the set of model parameters for which a social planner prefers negative money growth is larger. That is, taxing capital holding and subsidizing money holding is more often optimal. Consistent with the prediction of the Friedman rule, the optimal inflation rate might then be negative, even though the underlying rationale is very different.

However, this second pecuniary externality only exists in the presence of technological illiquidity, i.e. if $\kappa>0$. If capital can costlessly be converted into consumption and vice versa the price of capital $q$ is always 1 and capital shocks and real cash flow shocks have identical consequences.

Finally, note that our qualitative conclusion about the relationship between idiosyncratic risk and the optimal money growth rate continues to hold for this alternative shock structure. The findings that the optimal money growth rate is increasing with idiosyncratic risk and that the optimal money growth rate is positive, if risk is large relative to the discount rate, is robust to this variation of the model, whereas the exact condition for positivity of $\mu^{*}$ given in Proposition 4 is not.

\footnotetext{
${ }^{16}$ While the full proof of this result can be found in Appendix A.10 we want to illustrate its main idea for the special case of no capital adjustment costs, $\kappa=0$. In this case, the characterization of $\hat{\mu}^{*}$ from footnote 15 simplifies to

$$
\sqrt{\rho+\hat{\mu}^{*}}\left(2+\frac{\hat{\mu}^{*}}{\rho}\right)=\sigma .
$$

Since the left-hand side is increasing in $\hat{\mu}^{*}$, a higher $\sigma$ on the right must be accommodated by a higher $\hat{\mu}^{*}$ for the equation to hold.
} 


\section{Conclusion}

This paper contributes to the literature on the optimal steady state rate of inflation and hence on the optimal inflation target. It emphasizes the importance of financial frictions. Pecuniary externalities make the Friedman Rule supoptimal and destroy super-neutrality of money despite the absence of nominal rigidities. Inflation acts like a Pigouvian tax that corrects the pecuniary externalities due to financial frictions. Interestingly, it provides a rationale why emerging economies in which financial markets are less developed should have a higher inflation target - a description which fits reality.

\section{References}

AiYagaRI, S. R. (1994): "Uninsured Idiosyncratic Risk and Aggregate Saving," Quarterly Journal of Economics, 109(3), 659-684.

Angeletos, G.-M. (2007): "Uninsured Idiosyncratic Investment Risk and Aggregate Saving," Review of Economic Dynamics, 10(1), 1-30.

Bewley, T. F. (1980): "The Optimum Quantity of Money," in Models of Monetary Economies, ed. by J. H. Kareken, and N. Wallace. Federal Reserve Bank of Minneapolis.

Brunnermeier, M. K., And Y. SAnnikov (2014): "A Macroeconomic Model with a Financial Sector," American Economic Review, 104(2), 379-421.

(2015): "The I Theory of Money," Working Paper.

Calvo, G. A. (1983): "Staggered prices in a utility-maximizing framework," Journal of Monetary Economics, 12(3), 383-398.

Diamond, P. A. (1965): "National Debt in a Neoclassical Growth Model," American Economic Review, 55(5), 1126-1150.

Fraga, A., I. Goldfajn, and A. Minella (2004): "Inflation Targeting in Emerging Market Economies," in NBER Macroeconomics Annual 2003, vol. 18, pp. 365-416. The MIT Press.

International Monetary Fund (2005): "Does Inflation Targeting Work in Emerging Markets?," in World Economic Outlook, September, chap. 4.

Phelps, E. S. (1973): "Inflation in the Theory of Public Finance," The Swedish Journal of Economics, $75(1), 67-82$.

Samuelson, P. A. (1958): "An Exact Consumption-Loan Model of Interest with or without the Social Contrivance of Money," Journal of Political Economy, 66(6), 467-482.

Schmitt-Grohé, S., And M. Uribe (2010): "The Optimal Rate of Inflation," in Handbook of Monetary Economics, ed. by B. M. Friedman, and M. Woodford, vol. 3, chap. 13, pp. $653-722$. Elsevier.

Sidrauski, M. (1967): "Rational Choice and Patterns of Growth in a Monetary Economy," American Economic Review, 57(2), 534-544. 
Tobin, J. (1965): "Money and Economic Growth," Econometrica, 33(4), 671-684.

(1972): "Inflation and Unemployment," American Economic Review, 62(1), 1-18.

Woodford, M. (1990): "The optimum quantity of money," in Handbook of Monetary Economics, ed. by B. M. Friedman, and M. Woodford, vol. 2, pp. 1067-1152. Elsevier. 


\section{A Appendix}

\section{A.1 Proof of Lemma 1: Optimal Investment Rate}

Since only the current investment rate appears in the budget constraint, but no lagged or future investment rates, the choice of the optimal investment rate $\iota_{j}$ is an intra-period problem. The agent chooses $\iota_{j}$ in order to maximize total resources available for consumption and portfolio investments in the end of period $j$. This is achieved by maximizing

$$
q \Phi\left(\iota_{j}\right) \hat{k}_{j} \Delta t-\iota_{j} \hat{k}_{j} \Delta t
$$

which results in the - due to concavity of $\Phi$ also sufficient - first-order condition $q=\frac{1}{\Phi^{\prime}\left(\iota_{j}^{*}\right)}=1+\kappa \iota_{j}^{*}$.

If $\kappa>0$, this condition can be inverted to obtain $\iota_{j}^{*}$ and one sees that $\iota^{*}$ is a constant both over time and across agents.

In the case $\kappa=0$, the condition instead leads to $q=1$ and using the fact that $\Phi\left(\iota_{j}\right)=\iota_{j}$ one observes that A.1 vanishes in this case irrespectively of the choice of $\iota_{j}$. We therefore can also in this case impose a common investment rate $\iota^{*} 17$

\section{A.2 Return on Money and Transfers from Seignorage}

Recall that the evolution of the aggregate money stock is $M_{j+1}=(1+\mu \Delta t) M_{j}$ and that the real value of the money stock in period $j$ is assumed to be given by $p K_{j}$ with a time-invariant constant $p \geq 0$. The real rate of return on money from $j$ to $j+1$ is therefore

$$
R_{j+1}^{m}:=\frac{p K_{j+1} / M_{j+1}}{p K_{j} / M_{j}}=\frac{M_{j}}{M_{j+1}} \frac{K_{j+1}}{K_{j}}=\frac{1}{1+\mu \Delta t} \frac{K_{j+1}}{K_{j}}
$$

Due to Lemma 1 (constant investment rate) the (gross) growth rate of the capital stock between two successive periods is time-invariant and given by $1+g \Delta t$ with $g=\Phi\left(\iota^{*}\right)-\delta{ }^{18}$ Therefore, the real return on money is time-invariant as well and given by

$$
R_{j}^{m}=R^{m}=\frac{1+g \Delta t}{1+\mu \Delta t}
$$

Seignorage revenues in period $j$ are

$$
S_{j}:=\frac{M_{j}-M_{j-1}}{M_{j}} p K_{j}=\frac{\mu \Delta t}{1+\mu \Delta t} p K_{j} .
$$

Because they are redistributed to households in proportion to their wealth, a household with wealth $w_{j}$ must receive

$$
\frac{w_{j}}{(p+q) K_{j}} S_{j}=\frac{p}{p+q} \frac{\mu \Delta t}{1+\mu \Delta t} w_{j}
$$

\footnotetext{
${ }^{17}$ In the model without adjustment costs, there is an economically insignificant multiplicity in the problem with respect to the individual choices of $\iota_{j}$ : since physical investment and capital purchases on the capital market are from an individual household's point of view equally effective instruments to reach the desired target capital stock $k_{j+1}$, the identity of who makes physical investments and who buys capital on the market does not matter. The assumption, that everyone chooses the same investment rate is therefore without loss of generality.

${ }^{18}$ Compare also the discussion in the main text after the statement of Lemma 1
} 
The variable $\tau$ not fully specified in the main text is therefore given by

$$
\tau:=\tau(\Delta t):=\frac{p}{p+q} \frac{\mu \Delta t}{1+\mu \Delta t} .
$$

\section{A.3 Proof of Lemma 2; Optimal Consumption-Savings Decision}

Recall that the consumption problem is

$$
\max _{c}\left(\log c \cdot \Delta t+\frac{1}{1+\rho \Delta t} \alpha_{1} \log \left(w^{\prime}-c \Delta t\right)\right) .
$$

The first-order condition with respect to $c$ is

$$
0=\frac{1}{c} \Delta t-\frac{1}{1+\rho \Delta t} \alpha_{1} \frac{\Delta t}{w^{\prime}-c \Delta t} \Rightarrow c=\frac{w^{\prime}}{\Delta t+\frac{\alpha_{1}}{1+\rho \Delta t}}
$$

Substituting this back into the Bellman equation and using that the term depending on $x^{k}$ is independent of wealth verifies the conjectured form of the value function. By comparing coefficients one can recover $\alpha_{1}$ :

$$
\alpha_{1}=\Delta t+\frac{1}{1+\rho \Delta t} \alpha_{1} \Rightarrow \alpha_{1}=\frac{1+\rho \Delta t}{\rho}
$$

Consumption is thus given by

$$
c=\frac{w^{\prime}}{\Delta t+\frac{1}{\rho}}=\frac{\rho}{1+\rho \Delta t} w^{\prime}
$$

\section{A.4 Proof of Lemma 3: Solution to the approximated Portfolio Choice Problem}

The approximated portfolio choice problem is a quadratic optimization problem in $x^{k}$, thus the optimal $x^{k *}$ is just the linear coefficient divided by -2 times the quadratic coefficient, which yields exactly the result stated in Lemma 3 ,

\section{A.5 Proof of Proposition 1}

This Proposition just collects equations derived elsewhere in the paper. The first equation is from Lemma 1 the remaining two equations are the market clearing equations (1) and (2) derived in the main text.

\section{A.6 Proof of Proposition 2}

We prove this result in several steps. Some technical details are relegated to online appendix B.3 


\section{A.6.1 Formal Solution of Equilibrium Equations in Terms of $\hat{\mu}$}

Substituting $\mu=\frac{\hat{\mu}}{x^{k *}}=\frac{\hat{\mu}(p+q)}{q}$ into the equilibrium equations stated in Proposition 1 yields the equation system

$$
\begin{aligned}
q & =1+\kappa \iota^{*} \\
\rho(p+q) & =A-\iota^{*} \\
\frac{\sigma^{2}}{q+p} & =A-\iota^{*}+(p+q) \hat{\mu}
\end{aligned}
$$

Substituting the second into the third gives

$$
\frac{\sigma^{2}}{q+p}=(\rho+\hat{\mu})(p+q) \Rightarrow(p+q)^{2}=\frac{\sigma^{2}}{\rho+\hat{\mu}} \Rightarrow p+q= \pm \frac{\sigma}{\sqrt{\rho+\hat{\mu}}}
$$

Here, only the positive solution is reasonable. Substituting this result into the second equation yields

$$
\iota^{*}=A-\rho(p+q)=A-\rho \frac{\sigma}{\sqrt{\rho+\hat{\mu}}}
$$

and from the first one gets $q$ :

Finally, $p$ is given by

$$
q=1+\kappa \iota^{*}=1+\kappa A-\frac{\kappa \sigma \rho}{\sqrt{\rho+\hat{\mu}}}
$$

$$
p=p+q-q=\frac{\sigma}{\sqrt{\rho+\hat{\mu}}}-1-\kappa A+\frac{\kappa \sigma \rho}{\sqrt{\rho+\hat{\mu}}}=\frac{\sigma(1+\kappa \rho)}{\sqrt{\rho+\hat{\mu}}}-(1+\kappa A)
$$

\section{A.6.2 Equilibrium Existence under Assumption 1}

The formal solutions for $p$ and $q$ derived in part 1 might be negative, but under the assumption of free disposal of money and capital such equilibria cannot exist. Instead, the obtained solutions are only valid, if $p, q \geq 0$. In particular, then the total value of capital $q K_{t}$ must be positive and therefore also the share $\frac{q}{p+q}$ of aggregate wealth which is held in capital. In equilibrium this share coincides with $x^{k *}$, the common capital portfolio share chosen by all households, thus the condition $x^{k *}>0$ is necessary for an equilibrium with positive value of capital to exist. On the other hand, if $x^{k *}>0$, then due to $p+q \geq 0, q$ is also positive.

It is therefore sufficient to show that under Assumption 1 there is a solution to the equilibrium equations which implies $x^{k *}>0$ for any choice of $\mu$. This involves using the equilibrium equations to solve for $x^{k *}=q /(p+q)$ explicitly in terms of $\mu$, not just in terms of $\hat{\mu}=\mu x^{k *}-$ a tedious, but straightforward calculation, the interested reader can find in the online appendix B.3.1. Here, we only state the result.

Lemma A.1. Under Assumption 1, in any equilibrium with money and capital $x^{k *}$ is given by

$$
x^{k *}=\mu \frac{(1+\kappa A)^{2}}{2 \sigma^{2}}-\kappa \rho+\frac{1+\kappa A}{\sigma} \sqrt{\frac{\mu^{2}}{4}\left(\frac{1+\kappa A}{\sigma}\right)^{2}-\kappa \rho \mu+\rho}
$$

and this quantity is strictly positive for all $\mu$.

We conclude that the formal expression for $q$ in equation (4) is positive for all $\mu$ and that an equilibrium with money and capital exists, whenever $p$ is also nonnegative. 


\section{A.6.3 Parameter Restriction for Money to have Value in Equilibrium}

By free disposal money must have a nonnegative value in any equilibrium, i.e. $p \geq 0$. Comparing this with equation (3) yields the restriction

$$
\hat{\mu}<\sigma^{2}\left(\frac{1+\kappa \rho}{1+\kappa A}\right)^{2}-\rho
$$

for money to have positive value 19

\section{A.6.4 Moneyless Equilibrium}

In the economy without money (or where money does not have a positive value) there is no portfolio choice problem, instead all agents choose $x^{k}=1$. The derivation of the goods market clearing equation and the optimal physical investment rule remain valid, however. Hence, the equilibrium is described by the first two equations in Proposition 11, if one substitutes in $p=0$ :

$$
\begin{aligned}
q & =1+\kappa \iota^{*} \\
\rho q & =A-\iota^{*}
\end{aligned}
$$

One easily verifies, that $q=\frac{1+\kappa A}{1+\kappa \rho}, \iota^{*}=\frac{A-\rho}{1+\kappa \rho}$ solve this linear system.

\section{A.6.5 Monotonicity of "Transformed" Money Growth $\hat{\mu}$ in $\mu$}

This is implied by the following technical result $\hat{\mu}$ whose proof can be found in online appendix B.3.2

Lemma A.2. Under Assumption $11 x^{k *}(\mu)$ is a strictly increasing function in $\mu$.

\section{A.7 Calculation of the Undetermined Coefficients $\alpha_{0}, \alpha_{1}$ in the Value Func- tion}

The coefficient $\alpha_{1}$ was already determined in the proof of Lemma $2, \alpha_{1}=\frac{1+\rho \Delta t}{\rho}$, see equation A.2. Substituting this and the optimal choices $c$ and $x^{k}$ into the right-hand side of the Bellman equation yields

$$
\begin{aligned}
& \frac{1}{1+\rho \Delta t} \alpha_{0}+\log \left(\frac{\rho}{1+\rho \Delta t} w^{\prime}\right) \cdot \Delta t+\frac{1}{\rho} \log \left(w^{\prime}\left(1-\frac{\rho \Delta t}{1+\rho \Delta t}\right)\right)+\frac{1}{\rho} E\left[\log R^{p}\left(x^{k}\right)\right] \\
= & \frac{1}{1+\rho \Delta t} \alpha_{0}+\log \left(\frac{\rho}{1+\rho \Delta t}\right) \cdot \Delta t+\frac{1}{\rho} \log \left(\frac{1}{1+\rho \Delta t}\right)+\frac{1}{\rho} E\left[\log R^{p}\left(x^{k}\right)\right]+\frac{1+\rho \Delta t}{\rho} \log w^{\prime}
\end{aligned}
$$

$\alpha_{0}$ must be equal to the constant term in this expression (constant in the sense that it has no $w^{\prime}$ inside it), which yields an equation for $\alpha_{0}$. Solving for $\alpha_{0}$ and collecting all terms only depending on $\rho$ and $\Delta t$ but nothing else into a constant $V_{0}$ results in

$$
\alpha_{0}=V_{0}+\frac{1+\rho \Delta t}{\rho^{2}} \frac{E\left[\log R^{p}\left(x^{k}\right)\right]}{\Delta t}
$$

\footnotetext{
${ }^{19}$ In case this inequality holds with equality, $p=0$ and equations 3 , 4, 4, 5 coincide with the moneyless equilibrium.
} 


\section{A.8 Proof of Proposition 3}

Everything follows immediately from the arguments preceding the statement of the proposition.

\section{A.9 Proof of Proposition 4}

We prove the results in multiple steps. First, note that welfare is concave in a certain transformation of the objective.

Lemma A.3 (Concavity of Welfare). Welfare can be written as a function of the transformed policy variable $\phi:=\frac{\sigma}{\sqrt{\rho+\hat{\mu}}}$, which is a monotone (decreasing) transformation of $\hat{\mu}$ and in which it is strictly concave. The resulting expression is

$$
U=U_{0}+\frac{\frac{1}{\kappa} \log (1+\kappa A-\kappa \rho \phi)-\delta+\rho-\frac{1}{2} \frac{\sigma^{2}}{\phi^{2}}}{\rho^{2}}+\frac{\log \phi}{\rho}
$$

Proof. The continuous-time limit of welfare is

$$
U=U_{0}+\frac{\frac{1}{\kappa} \log \left(1+\kappa A-\frac{\kappa \rho \sigma}{\sqrt{\rho+\hat{\mu}}}\right)-\delta+\rho-\frac{1}{2}(\rho+\hat{\mu})}{\rho^{2}}+\frac{\log \left(\frac{\sigma}{\sqrt{\rho+\hat{\mu}}}\right)}{\rho} .
$$

The substitution $\phi=\frac{\sigma}{\sqrt{\rho+\hat{\mu}}}$ obviously leads to the expression stated in the assertion. In addition, this function is clearly concave in $\phi$.

All the claims of Proposition 4 are derived from the following simple lemma, whose proof can be found in online appendix B.4.1

Lemma A.4. The sign of $\frac{\partial U}{\partial \phi}$ is always identical to the sign of the function

$$
f:(0, \infty) \rightarrow(-\infty, \infty), f(\phi)=\left(\sigma^{2}+\rho \phi^{2}\right)(1+\kappa A-\kappa \rho \phi)-\rho \phi^{3}
$$

The set of potential values of transformed money growth $\mu^{*}$ is an open interval $(\underline{\hat{\mu}}, \infty) \subset(-\rho, \infty){ }^{20}$ and since the function

$$
(-\rho, \infty) \rightarrow(0, \infty), \hat{\mu} \mapsto \frac{\sigma}{\sqrt{\rho+\hat{\mu}}}
$$

is bijective, if is sufficient to show that there is a welfare-maximizing $\phi^{*} \in(0, \infty)$ with $\phi^{*} \leq \frac{\sigma}{\sqrt{\rho+\hat{\mu}}}=: \bar{\phi}$ to prove that there is a welfare-maximizing $\hat{\mu}^{*} \in(-\rho, \infty)$, which in turn implies the existence of a welfare-maximizing money growth rate $\mu^{*}$ by Proposition 2 .

Due to the concavity result in Lemma A.3 and the properties of $f$ defined in Lemma A.4 it is sufficient to prove $f(\bar{\phi})<0$ and $f(\underline{\phi})>0$ for some $\underline{\phi} \in(0, \bar{\phi})$. Then there must be an optimal $\phi^{*} \in(\phi, \bar{\phi})$. By choosing $\phi$ large enough, such that the corresponding value of $\hat{\mu}$ satisfies the condition A.4 for money to have value with equality, the strictly decreasing relationship between $\phi$ and $\hat{\mu}$ guarantees that the optimal $\hat{\mu}^{*}$ will satisfy A.4 with strict inequality, i.e. money has a positive value, if transformed money growth is $\hat{\mu}^{*}$.

For the value of $f$ at the upper bound $\bar{\phi}$ we deal with the cases $\kappa=0$ and $\kappa>0$ separately. If $\kappa=0$, then $q$ is always equal to 1 and thus $\bar{\phi}=\infty$. The terms of highest order in the polynomial $f$

\footnotetext{
${ }^{20} \underline{\hat{\mu}}$ is given by the value for $\hat{\mu}$ such that $q$ in equation 4 is 0 .
} 
have a negative coefficient, so $f(\phi) \rightarrow-\infty<0$ as $\phi \rightarrow \bar{\phi}=\infty$ in this case. If instead, $\kappa>0$, then the upper bound $\bar{\phi}$ is the unique value, such that

$$
0=q=1+\kappa A-\frac{\kappa \rho \sigma}{\sqrt{\rho+\hat{\mu}}}=1+\kappa A-\kappa \rho \bar{\phi},
$$

i.e. $\bar{\phi}=\frac{1+\kappa A}{\kappa \rho}$. Evaluating $f$ at this point yields

$$
f\left(\frac{1+\kappa A}{\kappa \rho}\right)=\left(\sigma^{2}+\rho \frac{(1+\kappa A)^{2}}{\kappa^{2} \rho^{2}}\right) \underbrace{\left(1+\kappa A-\kappa \rho \frac{1+\kappa A}{\kappa \rho}\right)}_{=0}-\rho\left(\frac{1+\kappa A}{\kappa \rho}\right)^{3}<0 .
$$
if

Next, we determine the lower bound $\phi$ such that A.4 is satisfied with equality. This is the case

$$
\underline{\phi}=\frac{1+\kappa A}{1+\kappa \rho} .
$$

Evaluating $f$ at this particular value of $\phi$ yields

$$
\begin{aligned}
f\left(\frac{1+\kappa A}{1+\kappa \rho}\right)= & \sigma^{2}(1+\kappa A)\left(1-\frac{\kappa \rho}{1+\kappa \rho}\right)+\rho \frac{(1+\kappa A)^{3}}{(1+\kappa \rho)^{2}}\left(1-\frac{\kappa \rho}{1+\kappa \rho}\right) \\
& -\rho\left(\frac{1+\kappa A}{1+\kappa \rho}\right)^{3} \\
= & \sigma^{2} \frac{1+\kappa A}{1+\kappa \rho}+\rho\left(\frac{1+\kappa A}{1+\kappa \rho}\right)^{3}-\rho\left(\frac{1+\kappa A}{1+\kappa \rho}\right)^{3} \\
= & \sigma^{2} \frac{1+\kappa A}{1+\kappa \rho}>0
\end{aligned}
$$

It is left to show the positivity condition for $\mu^{*}$ and the equation characterizing $\hat{\mu}^{*}$. The former result is obtained by evaluating $f$ at the $\phi$ value implied by $\mu=0$, i.e. $\phi=\sigma / \sqrt{\rho}$, whereas the latter is a simple reformulation of the condition $f\left(\phi^{*}\right)=0$ which is necessary and sufficient for optimality of $\phi^{*}$ due to the concavity of $U$ and Lemma A.4. Details are left out here and can be found in online appendix B.4.2 and B.4.3. For later reference we state here the equation characterizing $\hat{\mu}^{*}$ in a slightly different - but obviously equivalent - form:

Lemma A.5. The optimal money growth rate $\hat{\mu}^{*}$ is characterized by the equation

$$
0=\frac{1+\kappa A}{\rho}{\sqrt{\rho+\hat{\mu}^{*}}}^{3}-\kappa \sigma\left(\rho+\hat{\mu}^{*}\right)+(1+\kappa A) \sqrt{\rho+\hat{\mu}^{*}}-\sigma(1+\kappa \rho)
$$

\section{A.10 Proof of Proposition 5: Comparative Statics}

We show that the optimal $\hat{\mu}$ is strictly increasing in $\sigma$. Since $\hat{\mu}$ is strictly increasing in $\mu$, this implies the assertion.

The optimal $\hat{\mu}$ must satisfy the equation given in Lemma A.5.

$$
0=\frac{1+\kappa A}{\rho} \sqrt{\rho+\hat{\mu}}^{3}-\kappa \sigma(\rho+\hat{\mu})+(1+\kappa A) \sqrt{\rho+\hat{\mu}}-\sigma(1+\kappa \rho)
$$


One can rewrite this as follows

$$
(1+\kappa A) \frac{\sqrt{\rho+\hat{\mu}}^{3} / \rho+\sqrt{\rho+\hat{\mu}}}{\kappa(\rho+\hat{\mu})+\kappa \rho+1}=\sigma .
$$

The right-hand side is strictly increasing in $\sigma$, while the left-hand side does not directly depend on $\sigma$. Thus $\hat{\mu}$ is strictly increasing in $\sigma$, if and only if the left-hand side of this equation is strictly increasing in $\hat{\mu}$, which we prove in the following. For notational convenience, we show that the left-hand side is strictly increasing in $\psi:=\sqrt{\rho+\hat{\mu}}$. Since $\psi$ in turn is strictly increasing in $\hat{\mu}$, this is sufficient. In terms of $\psi$ equation A.5 can be stated as

$$
(1+\kappa A) \frac{\psi^{3} / \rho+\psi}{\kappa \psi^{2}+\kappa \rho+1}=\sigma
$$

Ignoring the positive constant term $(1+\kappa A)$, its left-hand side derivative is

$$
\begin{aligned}
\frac{\partial}{\partial \psi} \frac{\psi^{3} / \rho+\psi}{\kappa \psi^{2}+\kappa \rho+1} & =\frac{3 \psi^{2} / \rho+1}{\kappa \psi^{2}+\kappa \rho+1}-2 \kappa \frac{\psi^{4} / \rho+\psi^{2}}{\left(\kappa \psi^{2}+\kappa \rho+1\right)^{2}} \\
& =\frac{3 \kappa\left(\psi^{4} / \rho+\psi^{2}\right)+3 \psi^{2} / \rho+\kappa \psi^{2}+\kappa \rho+1}{\left(\kappa \psi^{2}+\kappa \rho+1\right)^{2}}-\frac{2 \kappa\left(\psi^{4} / \rho+\psi^{2}\right)}{\left(\kappa \psi^{2}+\kappa \rho+1\right)^{2}} \\
& =\frac{\kappa\left(\psi^{4} / \rho+\psi^{2}\right)+3 \psi^{2} / \rho+\kappa \psi^{2}+\kappa \rho+1}{\left(\kappa \psi^{2}+\kappa \rho+1\right)^{2}}>0
\end{aligned}
$$

